\title{
MÉTODOS Y TÉRMINOS TEÓRICOS EN LA DOGMÁTICA CONSTITUCIONAL
}

\section{Hume, Moore y los sistemas normativos}

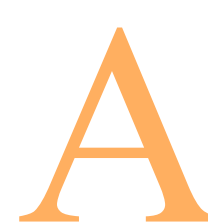

mediados del siglo XVIII David Hume, en su Tratado de la Naturaleza Humana, se abocó al estudio de la posibilidad conocimiento, y con relación a cuestiones morales («moral subjects») intentó demostrar que los sistemas de moral no pueden ser derivados de la razón.

Es allí donde el filósofo inglés formula la siguiente observación.

«En todo sistema de moral de que haya tenido noticia, hasta ahora, he podido observar que el autor sigue durante cierto tiempo el modo de hablar ordinario, estableciendo la existencia de Dios o realizando observaciones sobre los quehaceres humanos, y, de pronto, me encuentro con la sorpresa de que, en vez de las cópulas habituales de las proposiciones: «es» $y$ «no es», no veo ninguna proposición que no esté conectada con un «debe» $o$ "no debe». Este cambio es imperceptible, pero resulta, sin embargo, de la mayor importancia. En efecto, en cuanto que este «debe» o «no debe» expresa alguna nueva relación o afirmación, es necesario que ésta sea observada y explicada y que al mismo tiempo se dé razón de algo que parece absolutamente inconcebible, a saber: Cómo es posible que esta nueva relación se deduzca de otras totalmente diferentes. Pero como los autores no usan corrientemente de esta preocupación, yo tomo la libertad de recomendarla a los lectores y estoy persuadido de que esta ligera atención destruirá todos los sistemas corrientes de moral...» ${ }^{1}$

Esta idea de la imposibilidad de deducir enunciados de carácter prescriptivo a partir de enunciados descriptivos ha sido denominada «ley de Hume» o «falacia de Hume». Para el filósofo inglés existiría entonces «un abismo lógico» infranqueable entre enunciados descriptivos y enunciados de tipo normativo, como los de la ética o la moral.

En el siglo XX, George Edward Moore hablaría de la «falacia naturalista» («naturalistic fallacy») para referirse a la imposibilidad de derivar la ética de la metafísica y marcar el error de aquellos filósofos que identificaban lo «bueno» con cualquier propiedad natural.

\footnotetext{
${ }^{1}$ Hume, D., Tratado sobre la naturaleza humana, Madrid, 1986, pág. 656.
} 
En efecto, el concepto de falacia naturalista está también conectado con la idea de la necesaria bifurcación entre el «ser»y el «deber ser», entre los valores y los hechos, entre lo normativo y lo descriptivo. Según Frankena ${ }^{2}$ muchos «moralistas», en especial los intuicionistas, consideraron apropiado bautizar como «falacia naturalista» al intento de derivar «debe» de «es» en el ámbito de la ética. Es por ello que muchas veces las expresiones «falacia de Hume», «ley de Hume» y/o «falacia naturalista» son utilizadas indistintamente, a pesar de que esta última va algo más allá que lo expresado en el célebre párrafo de Hume.

La falacia naturalista en sentido estricto puede hacer referencia a una de estas tres ideas:

(i) las proposiciones éticas no son deducibles de las no éticas.

(ii) las propiedades éticas no pueden ser definidas en términos no éticos.

(iii) las propiedades éticas son diferentes de las no éticas ${ }^{3}$.

Un ejemplo clásico de comisión de la falacia naturalista está constituido por el argumento epicúreo que tomara Mill en favor del hedonismo, de acuerdo con el cual el placer es bueno, dado que es perseguido por todos los hombres. En este caso se ve claramente cómo una conclusión ética («el placer es bueno») es derivada de premisas no éticas («el placer es perseguido por todos los hombres»). Tanto Hume como Moore intentaron mostrar que no se puede deducir que el placer sea bueno (plano ético-normativo) del hecho de que todos los hombres busquen el placer (plano descriptivo). ${ }^{4}$

En este trabajo tomaremos las expresiones «falacia de Hume», «ley de Hume» y «falacia naturalista» como sinónimas ${ }^{5}$ y haciendo referencia a:

${ }^{2}$ Frankena, W., «The Naturalistic Fallacy», en Theories of Ethics, Oxford University Press, 1970, págs. $50 \mathrm{y}$ ss.

${ }^{3}$ Frankena, W., op. cit., pág. 55.

${ }^{4}$ De acuerdo con Nino, el punto en que primordialmente se ponen de manifiesto los problemas de la tesis de Mill, es en su «prueba del principio de utilidad» según la cual, del hecho de que todos los hombres deseen su propio placer o felicidad se sigue que es deseable el placer o la felicidad de todos. Mill incurriría aquí en dos falacias: la naturalista, dado que se daría una confusión entre lo deseado de hecho y lo deseable, siendo esto lo que lo lleva a pasar del ser al deber ser, y la falacia de composición, a través de la cual, de la afirmación de que todos los hombres desean su propia felicidad, se pasa a la afirmación de que para cada hombre es deseable la felicidad de todos los hombres. Conf. Nino, C., Introducción al análisis del derecho, Bs. As., 1987, pág. 393.

${ }^{5}$ Ello por cuanto concordamos con Ayer en que la falacia naturalista constituye un «hallazgo ilusorio», pues si existe, su comisión se producirá cuando se defina «"bueno" de una forma tal que no implique que lo que es bueno es algo que haya que buscar o hacer». Según este autor, Moore no hace otra cosa que repetir el argumento de Hume, ya que lo que en definitiva sostiene es que «bueno» es un concepto normativo y que por lo tanto es erróneo otorgarle un significado puramente descriptivo. Ayer avanza aún más y acusa al propio Moore de haber cometido la falacia que denuncia cuando, al sostener que «bueno» no podría reemplazarse por 
a) que existe una clase de enunciados, los descriptivos, que son diferenciables, desde

el punto de vista del uso del lenguaje, de los enunciados de carácter normativo, y

b) que no es posible derivar enunciados normativos a partir de enunciados descriptivos.

Como hemos visto, la disputa en tomo a la posibilidad de derivar el «deber ser» del «ser» se desarrolló en tomo al discurso ético. Sin embargo, los alcances de la falacia de Hume, tal como aquí ha sido planteada, no se agotan en ello, sino que se extienden a todo conjunto normativo, y por lo tanto comprenden también al derecho.

A pesar de la claridad de la distinción entre enunciados descriptivos y enunciados normativos y al obstáculo que supone la falacia de Hume para transitar de unos a otro, en los estudios de derecho no es poco frecuente detectar el intento de trasponer este «abismo lógico» entre ser y deber ser. ${ }^{6}$

Muchas veces los juristas pretenden ajustar el derecho a ciertas exigencias tales como la completitud, la coherencia, la justicia, etc. Para ello es menester modificar los sistemas jurídicos, superando sus deficiencias. Sin embargo la adecuación a tales ideales no es presentada como una propuesta de modificación, sino que se recurre a una serie de construcciones y artilugios retóricos intentando demostrar que esa es la «verdadera» interpretación del sistema y/o que la misma se deriva lógicamente del mismo. Entre ellas podemos mencionar a las tristemente célebres apelaciones a las «naturalezas jurídicas» ${ }^{7}$, las definiciones reales, la subsunción de la solución en un principio general de mayor alcance que las normas que justifican, la adscripción de soluciones al legislador bajo el presupuesto de su racionalidad,

ninguna propiedad natural, infirió de ello que se trataba de una cualidad no natural. Conf. Ayer. A., $L a$ filosofía del siglo XX, Barcelona, 1983, pág. 61.

${ }^{6}$ Hans Kelsen ha puesto reiteradamente el toque de alerta sobre este problema en la órbita del derecho: «Nadie puede negar que la afirmación de que "algo es" -esto es, el enunciado con el cual se describe un hecho real-, es esencialmente diferente del enunciado que dice que "algo debe producirse", esto es: del enunciado con el cual se describe una norma y que, en consecuencia, de que algo exista no puede seguirse que algo deba existir, de igual modo a que de algo deba ser, no puede seguirse que algo sea...». Kelsen, H., Teoría Pura del Derecho, México, 1979, págs. 19 y 20.

${ }^{7}$ Para un análisis crítico en torno a la «búsqueda» de las «naturalezas jurídicas» véase Bulygin, E., Naturaleza jurídica de la letra de cambio, Bs. As., 1961; Carrió, G., Notas sobre derecho y lenguaje, Bs. As., 1987; y Nino, C., op. cit., pág. 336. La dogmática constitucional también recurre a su utilización. Véase a modo de ejemplo, Medina Rubio, R., La función constitucional de las comisiones parlamentarias de investigación, Madrid, 1994, con relación a la naturaleza jurídica de las comisiones parlamentarias de investigación; Pérez-Serrano Jáuregui, N., Los grupos parlamentarios, Madrid, 1989, donde se dedica un capítulo a la naturaleza jurídica de los grupos parlamentarios; Sagüés, N., Elementos de Derecho Constitucional, Bs. As., 1993, que analiza la naturaleza jurídica del municipio de la Capital Federal, de las Provincias, del juicio político, etc. 
etc. ${ }^{8}$ Es decir, los juristas encubren su «función normativa» mediante un arsenal teórico, algunas de cuyas armas intentaremos analizar en este trabajo.

\section{La falacia de Hume y las bases filosóficas de la dogmática constitucional}

Para mejor comprender las herramientas teóricas que se utilizan en el ámbito de la teoría constitucional, intentaremos describir muy sucintamente el telón de fondo sobre el que las mismas se recortan.

Cuando hacia el siglo XVII se comienza a discriminar entre ciencias racionales y ciencias empíricas, el estudio del Derecho fue ubicado entre las primeras. Las corrientes iusnaturalistas racionalistas predominantes en dicha época, con exponentes como Grocio y Pufendorf, entre otros, presentaban la elaboración de detallados sistemas de «derecho natural» como principios autoevidentes que hacían las veces de axiomas a partir de los cuales se deducían lógicamente normas jurídicas positivas. ${ }^{9}$ Los juristas estudiaban, no las normas vigentes, sino las que debían regir según los postulados que conformaban el derecho natural».

Hacia el siglo XIX, con el inicio del proceso de la codificación, sumado a otros factores políticos y filosóficos, se produjo un giro en la actividad de los juristas, muchos de los cuales dejaron de lado los principios universales y eternos del derecho natural y los sustituyeron por las normas del derecho positivo. Es decir, las normas emanadas del legislador pasaron a constituir, en esta nueva etapa, los axiomas de la «ciencia del derecho»». ${ }^{10}$ Cuando el iusnaturalismo racionalista se enfrentó a esta nueva realidad de la codificación, no modificó sus métodos sino que se abocó a la tarea de aprehenderla a partir de los mismos presupuestos y métodos de corte abstracto y metafísico propios del racionalismo. ${ }^{11}$ Las creencias de que la legislación es la fuente principal del derecho y de que el orden jurídico es preciso, completo y coherente se convirtieron en premisas no sujetas a comprobación intersubjetiva,

\footnotetext{
${ }^{8}$ Conf. Nino, C., op. cit., págs. 328 y ss.

${ }^{9}$ Cabe aclarar que, tal como gentilmente nos comentara el Dr. Bulygin, la filosofía del derecho de Kant no es asimilable a la de estos autores, aunque presente influencias iusnaturalistas. En el mismo sentido Muguerza afirma que el llamado «derecho racional» kantiano (Vernunftrecht) no se identifica con el derecho natural tradicional, ni siquiera el racionalista. Conf. Muguerza, J., La alternativa del disenso. (En torno a la fundamentación ética de los derechos humanos), en Muguerza, J. y otros., El fundamento de los derechos humanos, Madrid, 1989, pág. 22.

${ }^{10}$ Conf. Alchourrón, C. y Bulygin, E., Introducción a la metodología de las ciencias jurídicas y sociales, Bs. As., 1987, págs. 89/90.

${ }^{11}$ Conf. González Vicén, F., «Sobre los orígenes y supuestos del formalismo en el pensamiento jurídico contemporáneo», en Anuario de Filosofía, Madrid, 1961, citado por Nino, C., op. cit., pág. 337.
} 
constituyéndose en un dogma para la mayor parte de los emprendimientos teóricos contemporáneos en materia jurídica. Esto hizo que el discurso de la «dogmática jurídica» no asumiera las características de un discurso meramente cognoscitivo y que asumiera como finalidad la reformulación del derecho positivo a fin de adecuarlo a sus ideales de precisión, completitud y coherencia, y a determinadas preferencias axiológicas. Para realizar esa tarea los juristas debieron elaborar un aparato conceptual que les permitiera hacer aparecer como implícitas o derivadas del derecho positivo soluciones que, en realidad, eran de su propia manufactura.

La teoría constitucional parece no escapar de las influencias de este modelo teórico que naciera en el siglo pasado. La actitud que asumen no solo los teóricos sino también los jueces frente a la interpretación de las normas constitucionales, esconde tras de sí una serie de presupuestos tales como la completitud y la coherencia de los sistemas normativos y la precisión y univocidad del lenguaje de las normas propias del paradigma descripto.

A lo anterior debemos adicionar que varios de los doctrinarios del derecho constitucional adhieren a enfoques filosóficos de corte iusnaturalista que obviamente influirán también sobre su metodología y sobre los términos teóricos que empleen.

El iusnaturalismo podría caracterizarse, siguiendo al profesor Carlos Nino ${ }^{12}$, a través de dos tesis:

1. Existe un derecho natural, es decir, un conjunto de principios morales y de justicia de carácter objetivo, cognoscibles a través de la razón humana.

2. Para que un sistema normativo sea considerado jurídico debe adecuarse a los principios del derecho natural.

Ahora bien, la afirmación de la existencia de un conjunto de normas universalmente válidas y cognoscibles, capaces de suministrar criterios de juridicidad, trae aparejadas una serie de dificultades que será necesario tener presentes por sus implicancias epistemológicas.

Desde el punto de vista epistemológico, el primer problema que se plantea es determinar cuál es la fuente del derecho natural. En esto los iusnaturalistas se encuentran muy lejos de brindar una respuesta unánime: «Dios», la «naturaleza», la «razón humana»...

Pero no sólo discrepan en cuanto al origen del derecho natural: también existen profundos desacuerdos en cuanto a su contenido. En efecto, el derecho natural ha sido utilizado para justificar el absolutismo (Hobbes) y la democracia (Rousseau), la propiedad privada (Grocio, Locke) y la propiedad

\footnotetext{
${ }^{12}$ Nino, C., op. cit., pág. 28.
} 
colectiva (Morelly), la conservación del statu quo (Aristóteles) y la revolución (Rousseau). ${ }^{13}$

Un intento por salvar este enorme obstáculo lo constituye el interpretar que el contenido del derecho natural es «progresivo», esto es, que si bien estaría conformado por un núcleo de principios inmutables, se diversificaría en sus determinaciones históricas. El derecho positivo toma esos principios y los adapta a las condiciones históricas propias de las comunidades. ${ }^{14}$

Pero en tal caso deberíamos admitir que, si los principios siempre son los mismos y lo que hace el derecho positivo es adaptarlos a un momento histórico particular, analizando la historia del hombre se concluye que, o bien dentro del derecho natural existen principios contradictorios -que nos permiten justificar tanto la esclavitud en la antigüedad, lo cual implica la negación del status de persona a ciertos seres humanos, como la afirmación de que todos los seres humanos poseen ciertos derechos por el sólo hecho de ser hombres, en el siglo XX-, o bien que el hombre malinterpretó o no descubrió en tales casos el «verdadero» principio. Ambas conclusiones serían inaceptables para un iusnaturalista ya que, si los principios morales fueran contradictorios, cualquier otro sería a partir de ellos derivable, y por otra parte, todo partidario de esta postura también afirma que esos principios son cognoscibles y autoevidentes.

El tercer problema se relaciona con el método a través del cual se podría acceder a los contenidos del derecho natural. Generalmente se habla de la intuición, ${ }^{15} \mathrm{o}$ algún tipo de revelación o captación directa o evidente, que son incompatibles con uno de los principales requisitos de la ciencia moderna cual es el del control intersubjetivo.

Estos problemas, el de la identificación de las fuentes, la determinación de cuáles son los principios o valores morales y el del método para su conocimiento, son extensibles también a otras propuestas que si bien generalmente

${ }^{13}$ Conf. Kelsen, H., «La doctrina del derecho natural ante el tribunal de la ciencia», en ¿Qué es la justicia? Buenos Aires, 1993, págs. 64-111.

${ }^{14}$ Ver Padilla, M., Lecciones de derechos humanos y garantías constitucionales, Bs. As., 1993, págs. 27 y ss.; Bidart Campos, G., «Dogmática constitucional de los derechos humanos. (El derecho natural en el derecho constitucional de los derechos humanos)», en A.A.D.C. Boletín informativo, Bs. As., agosto de 1993.

${ }^{15}$ Bidart Campos y Sagüés hablan por ejemplo de la «intuición eidética», que permitiría seleccionar entre distintas valoraciones el criterio o parámetro de valor. El último introduce una serie de «métodos» a través de los cuales se podrían efectuar ciertas correcciones en el descubrimiento de los criterios de valor. Entre ellos, el método de «fraccionamiento», que «advierte que nunca es posible una justicia o legitimidad perfecta en el mundo jurídico», parece admitir algunas de las deficiencias que tradicionalmente denunciara el positivismo como por ejemplo el hecho de que un acto reputado hoy como justo puede no serlo mañana. Conf. Sagüés, N., Elementos de Derecho Constitucional, Bs. As., 1993, T. I, pág. 73 y ss. y Bidart Campos, G., op. cit., pág. 2 y ss. 
no son consideradas iusnaturalistas en sentido estricto, postulan la existencia de ciertos valores cognoscibles de carácter objetivo que deben ser tenidos en cuenta por la ciencia del derecho. ${ }^{16}$

Hechas estas aclaraciones, pasaremos a analizar en primer lugar ciertas cuestiones vinculadas con lo metodológico, para luego hacer lo propio con algunos conceptos teóricos específicos de la disciplina.

\section{Algunos aspectos metodológicos en la dogmática constitucional}

a) La interpretación

La interpretación es entendida como la tarea a través de la cual se intenta establecer el sentido de las normas. ${ }^{17} \mathrm{La}$ interpretación supondría dos cosas:

a) que el intérprete retrocede mentalmente al momento de la creación de la norma y a la voluntad creadora en igual momento;

b) que el intérprete confronta el sentido que a la norma le asigna la comunidad actual con el sentido que le atribuyó el autor. ${ }^{18}$

En materia de interpretación, tanto en la doctrina constitucional como en la jurisprudencia se presenta la dicotomía entre dos tipos de interpretación:

- Interpretación literal: la que procura establecer el sentido de las palabras del texto normativo. En ella el intérprete debe «combinar el sentido común con el sentido técnico y considerar a la norma integrada en el contexto donde está ubicada ${ }^{19}$.

- Interpretación histórica: la que trata de desentrañar la «voluntad real e histórica», la «intención» del autor de la norma. ${ }^{20}$

\footnotetext{
${ }^{16}$ Por ejemplo la teoría egológica de Carlos Cossio, seguida entre otros constitucionalistas por los profesores argentinos Segundo Linares Quintana y Humberto Quiroga Lavié.

${ }^{17}$ Conf. Bidart Campos, G., Tratado elemental de Derecho Constitucional Argentino, Bs. As., 1986, T. I, pág. 67; Linares Quintana, S., Reglas para la interpretación constitucional, Bs. As., 1987; y Sagüés, N., op. cit., T. I, pág. 51.

${ }^{18}$ Bidart Campos, G., Tratado Elemental de Derecho Constitucional Argentino, ya citado, pág. 67; Willoughby, W., The Constitutional Law of the United States, citado en Linares Quintana, S., Reglas para la interpretación constitucional, ya citado, pág. 73.

${ }^{19}$ Bidart Campos, G., Tratado Elemental de Derecho Constitucional Argentino, ya citado, pág. 67; Linares Quintana, S., Reglas para la interpretación constitucional, ya citado, pág. 73. La Corte Suprema de la República Argentina pareció privilegiar esta interpretación en un primer momento, tal lo que surge de los casos «Mórtola» $\mathrm{y}$ «Lara». Conf. Sagüés, N., op. cit., T. I, pág. 54.

${ }^{20}$ Conf. Bidart Campos, G., Tratado Elemental de Derecho Constitucional Argentino, ya citado, pág. 67; Fiore, P., De la irretroactividad e interpretación de las leyes, Madrid, 1927, citado por Linares Quintana, S., en Reglas para la Interpretación Constitucional, ya citado; Ramella, P., Derecho constitucional, Bs. As., 1986, pág. 14. La Corte Suprema Argentina en el caso «Piccardo» (citado por Sagüés, N., op. cit., T. I, pág. 54) dijo que «el fin primordial del intérprete es dar pleno efecto a la voluntad del legislador».
} 
La clasificación descripta da cuenta de dos actitudes interpretativas que generalmente se asumen frente a un texto lingüístico: la interpretación subjetiva, que centra su atención en la intención que tuvo el que formuló el enunciado, y la interpretación objetiva, que hace hincapié sobre lo que efectivamente dijo el autor del texto, sobre el significado que poseen sus palabras en el lenguaje ordinario, o como dice Alf Ross, «sobre el significado que está en la comunicación como tal, considerada como un hecho objetivo» ${ }^{21}$.

Con relación a la interpretación subjetiva se debe reconocer que es imposible acceder a la voluntad o intención del autor de la norma. Por lo tanto, hablar de interpretación subjetiva significa que, además de la expresión lingüística, se hace hincapié en otros datos que se consideran relevantes: la situación histórica, la ideología política, el propósito expreso o aquello que guió a formular la expresión, etc. ${ }^{22}$

En cuanto al otro camino interpretativo, consideramos que una expresión como tal no tiene necesariamente un significado objetivo preciso. El mismo dependerá de las propiedades o datos que el intérprete considere relevantes y de sus propias ideas y conjeturas acerca del texto normativo: «la creencia en la interpretación literal es una ilusión.... ${ }^{23}$.

Es por ello que coincidimos con Alf Ross en que, tomada la distinción mencionada -interpretación subjetiva e interpretación objetiva- como un contraste absoluto entre lo que se quiere decir y lo que se dice, la misma es insostenible. Toda interpretación será perspectivada, en el sentido de que en uno u otro caso será el intérprete el que escogerá qué elemento o circunstancia considera de importancia para determinar el sentido de una norma. $\mathrm{Y}$ es importante tener esto en cuenta para no caer en el error de tomar a un determinado método o técnica interpretativa como una herramienta «esterilizada» a través de la cual accederemos al «verdadero» sentido de la norma.

Uno de los aspectos más discutidos de la interpretación constitucional está constituido por la llamada «interpretación mutativa». Según este tipo de interpretación, se admite que el intérprete modifique el significado de la norma manteniendo intacto su texto: la interpretación mutativa «modifica la constitución sin alterar su letra o espiritu» ${ }^{24}$.

Tanto la doctrina como la jurisprudencia consideran legítimo este método interpretativo para complementar el texto constitucional, a lo que se califica

\footnotetext{
${ }^{21}$ Ross, A., Sobre el derecho y la justicia, Bs. As., 1963, pág. 117.

${ }^{22}$ La interpretación, entendida como aprehensión de la supuesta voluntad histórica del legislador real, se conoce como «exégesis» y presupone la tesis ontológica de que el derecho es un modo de la voluntad, identificándose esa voluntad con la voluntad de algún legislador real. Conf. Vernengo, R., Curso de Teoría General del Derecho, Bs. As., 1985, pág. 413.

${ }^{23}$ Ross, A., op. cit., pág. 118.

${ }^{24}$ Bidart Campos, G., Tratado Elemental de Derecho Constitucional Argentino, ya citado, pág. 68. En el mismo sentido Sagüés, N., op. cit., pág. 56 y Ramella, P., op. cit., pág. 14.
} 
de mutación «praeter constitutionem». Para el caso en que la interpretación sea manifiestamente contraria al texto de la constitución, esto es, «contra constitutionem», algunos también la admiten si se trata de «un fenómeno jurídico ya consumado», haciendo referencia a los efectos que la costumbre puede ejercer sobre la eficacia de una norma. ${ }^{25}$

Ocurre que la expresión «norma» es ambigua, dado que puede entenderse por ella tanto el texto, la oración, el conjunto de palabras, como también el mensaje que se expresa a través de ellos.

Es aquí donde debemos recordar la distinción existente entre norma y formulación de la norma. La formulación de la norma es el texto a través del que se expresa la norma. ${ }^{26}$ Es decir, que en el lenguaje normativo deberíamos distinguir entre:

- los símbolos, el texto propiamente dicho (formulación normativa) y,

- la norma, es decir el mensaje contenido en la formulación normativa.

En el discurso de la dogmática es muy común la utilización del término «norma»en sentido restringido, haciendo referencia solamente a la formulación normativa, como vimos ocurre con la llamada «interpretación mutativa». De esta forma todo cambio de interpretación no sería considerado una modificación del sistema jurídico, ya que la misma se produciría únicamente mediante la intervención del legislador.

Sin embargo la distinción introducida por von Wright nos muestra que esto no es así. Cuando se produce un cambio en la interpretación de la formulación normativa se modifica la norma y por lo tanto el sistema jurídico. Si interpretamos «norma» junto a Alchourrón y Bulygin como aquel enunciado que correlaciona un caso con una solución, un cambio en la interpretación significa un cambio en la correlación, y estamos por lo tanto ante una nueva norma. ${ }^{27}$ La interpretación mutativa justificaría entonces la posibilidad de colmar las lagunas normativas, tema que analizaremos en el punto siguiente.

Por otra parte, tenemos la cuestión de la existencia o no de jerarquías en las declaraciones de derechos de las constituciones. Por ejemplo, la Constitución argentina en su parte dogmática no incluye ningún orden jerárquico entre los derechos en ella reconocidos. La Corte Suprema de Justicia y gran parte de la doctrina nacional sostienen que los derechos fundados en cualquier

\footnotetext{
${ }^{25}$ Sagüés, N., op. cit., pág. 59. En contra, Ramella, P., op. cit., pág. 15.

${ }^{26}$ Conf. von Wright, G. H., Norma y acción, una investigación lógica, Madrid, 1979, págs. 109 y ss.

${ }^{27}$ Conf. Bulygin, E., «Dogmática jurídica y sistematización del derecho», en Análisis Lógico y Derecho, Madrid, 1991,pág. 469.
} 
cláusula de la Constitución tienen igual jerarquía y que en caso de colisión entre algunos de ellos la interpretación debe armonizarlos. ${ }^{28}$

En cambio, otros sostienen que entre los derechos constitucionales sí existe una escala jerárquica. Como ejemplo paradigmático el profesor Ekmekdjian parte de la idea de que los derechos son accesorios de los valores y que estos últimos están ordenados jerárquicamente. De esto concluye que los derechos constitucionales también están ordenados jerárquicamente..$^{29}$

Para construir dicha escala Ekmekdjian tiene en cuenta la razonabilidad, la mayor o menor restringibilidad del derecho subjetivo que protege al valor, el método de las «sustracciones hipotéticas» que consiste en imaginar un mundo en el cual se negara una categoría de derechos (valores) y otro que si lo aceptara juzgando cuál pérdida es más importante, la medición de la posibilidad de renuncia del derecho por su titular, y por último la intuición. Todo esto le permitiría señalar el valor más significativo en forma unívoca. Creemos que esta teoría adolece ella misma de la falacia de Hume. En efecto, el intento del autor de presentar la «verdadera» escala jerárquica de valores y, consecuentemente, de derechos subjetivos, a partir de una serie de métodos que, si bien son presentados como «fundamentalmente jurídicos» ${ }^{30}$, poseen un alto grado de subjetivismo y poco sustento normativo, acercan a esta propuesta más a las preferencias particulares del constitucionalista que a la descripción objetiva de nuestro sistema jurídico. ${ }^{31}$ En definitiva, sería pasible de las críticas ya formuladas respecto del iusnaturalismo.

La expresión «sistema normativo» también es ambigua y con ella puede hacerse referencia a un conjunto de normas o bien a un conjunto jerárquicamente ordenado de normas. Cuando se introduce un orden jerárquico en un determinado conjunto de normas, es decir, se establece una preferencia de una norma sobre otra, se modifica el sistema, ya que la jerarquía implica

\footnotetext{
${ }^{28}$ Ver casos «Dri, A. c/ Gobierno Nacional», CSJN, LL-123-156; «Lopardo s/ insubordinación», CSJN 26/10/82, J.A. 1983-III 253; «Campillay c/ La Razón», LL 1986-C-411 de la Corte Suprema argentina, entre otros. Criterio similar adopta el Tribunal Constitucional español que ha manifestado: «... ha de hacerse considerando a la Constitución como un todo en el que cada precepto encuentra su sentido pleno valorándolo en relación con los demás, es decir, de acuerdo con una interpretación sistemática...», sentencia del 4/2/83 citada en Pérez Luño, A. E., Sobre los valores fundamentadores de los derechos humanos, en Muguerza, J. y otros, ya citado, pág. 288.

${ }^{29}$ Conf. Ekmekdjian, M., «Temas constitucionales», Bs. As., 1987, págs. 17 y 18, 23 a 29, 44 a 46. Ver también «M. de B., P. c/ Editorial L., S.A.», CNCiv., Sala A, LL, 126-466, 1987.

${ }^{30}$ «... utilizaremos un instrumental fundamentalmente jurídico para elaborar nuestra escala...», Ekmekdjian, M., op. cit., pág. 24.

${ }^{31}$ El propio autor prevé en uno de sus trabajos las dificultades que podría entrañar su teoría: «... esta tarea es asaz difícil, por cuanto no hay nada más teñido de subjetividad que una teoría de valores...», Ekmekdjian, M., op. cit., pág. 24.
} 
derogación de ciertas normas inferiores. ${ }^{32}$ En otras palabras, aún cuando las normas sean las mismas, desde el momento que se introduce o se modifica la jerarquía entre ellas estamos ante un nuevo sistema. De tal manera, los juristas, apelando a esta ambigüedad, podrían modificar los sistemas jurídicos sin «tocar» las normas, mediante la introducción de jerarquías que se presentan también como derivadas del propio sistema.

$\mathrm{Si}$ analizamos la teoría sustentada por ejemplo por la Corte Suprema argentina, en un primer momento parece dejar intacto el sistema de la constitución al interpretar el silencio del constituyente sobre el tema como «igual jerarquía». Sin embargo, cuando introduce la idea de que en caso de colisión de derechos en el caso concreto, los mismos deben ser interpretados en forma «armónica», se abre la puerta a infinidad de nuevos sistemas jurídicos. Con la idea de «interpretación armónica», se está legitimando al Alto Tribunal para que en cada caso concreto en que se presente un conflicto, él establezca un nuevo orden jerárquico.

En resumen, como hemos visto, en el ámbito de la dogmática constitucional los diferentes métodos interpretativos son propuestos como verdaderas herramientas para que el propio jurista e intérpretes -operadores -como el juez y el legislador- puedan «acceder» al significado de las normas. ${ }^{33}$

Cabe el interrogante de si los métodos interpretativos así concebidos no presentan una doble faceta que facilita su utilización ideológica. Se plantean como técnicas de carácter puramente cognoscitivo, en el sentido de que sirven para «desentrañar» una "comunicación normativa» confusa u oscura, o incluso «incompleta», pero sin embargo, asumen el papel de «técnicas socialmente prestigiosas» ${ }^{34}$ para la orientación de los órganos de creación y sobre todo de aplicación de las normas generales.

Es aquí cuando se produce el «salto vedado»: los métodos interpretativos aparecen así como prescripciones destinadas a los mencionados órganos, y también son presentados como verdaderas reglas de derivación normativa implícitas en el ordenamiento jurídico.

\section{b) Las lagunas y la actitud del jurista}

Todos los teóricos del derecho constitucional son contestes en admitir la existencia de lagunas en los sistemas jurídicos. Generalmente se distingue entre lagunas normativas y lagunas axiológicas.

${ }^{32}$ Alchourrón, C. y Bulygin, E., «La concepción expresiva de las normas», en Análisis Lógico y Derecho, ya citado, págs. 144 y ss.

${ }^{33}$ Ver por ejemplo el completísimo panorama de métodos que propone Linares Quintana en Tratado de la ciencia del derecho constitucional argentino y comparado, Bs. As., 1953, T. I, pág. 373 y ss.

${ }^{34}$ Vernengo, R., op. cit., pág. 413. 
Las primeras se producen cuando existe un "vacío normativo», ${ }^{35}$ cuando a un determinado caso el sistema jurídico no correlaciona ninguna solución. ${ }^{36}$

En las llamadas «lagunas axiológicas», en cambio, sí existe una solución para el caso, pero el intérprete considera que la misma es injusta.

$\mathrm{Al}$ respecto, se ha dicho: «Supongamos que hay una norma, que la voluntad del autor no ha -sido insuficiente como en el caso de las lagunas referidas, pero que la norma que hay nos parece injusta, y que por su injusticia queremos prescindir de ella y no aplicarla. Esto se llama carencia dikelógica de norma que proviene de descartar la norma injusta...» ${ }^{37}$. Concordantemente, se ha señalado que hay laguna axiológica cuando «... la constitución trata injustamente un tema dándole una solución tan ilegítima que no debe obedecerse (caso de derecho en sentido impropio o "derecho aparente» lesivo de principios fundamentales de derecho natural)...» ${ }^{38}$.

¿Cuál es la actitud que asume el intérprete frente a estos dos problemas?

Respecto de las lagunas axiológicas, aquellos que han abordado el tema coinciden en que la norma debe ser dejada de lado y, si fuera necesario, crear una norma justa que la sustituya. Así, algunos abiertamente sostienen que el juez debe declarar inconstitucional a la norma injusta. ${ }^{39}$

Respecto de las lagunas normativas se sostiene que el jurista debe elaborar la norma faltante. A esto se lo denomina «procedimiento de integración». ${ }^{40}$

La integración se llevaría a cabo de dos maneras:

a) cuando el vacío es llenado con elementos del propio sistema jurídico mediante la analogía o recurriendo a principios generales del derecho positivo constitucional, se habla de «autointegración»;

\footnotetext{
${ }^{35}$ Sagüés, N., op. cit, pág. 64. En igual sentido Bidart Campos, G., Tratado Elemental de Derecho Constitucional Argentino, ya citado, pág. 67.

${ }^{36}$ Alchourrón, C. y Bulygin, E., Introducción a la metodología de las ciencias jurídicas y sociales, ya citado, pág. 41.

${ }^{37}$ Bidart Campos, G., Tratado Elemental de Derecho Constitucional Argentino, ya citado, págs. 67 y ss.

${ }^{38}$ Sagüés, N., op. cit., pág. 64. En igual sentido Bidart Campos, G., Tratado Elemental de Derecho Constitucional Argentino, ya citado, pág. 67.

${ }^{39}$ Su primer intento ha de procurar encontrar en la constitución algún principio o algún artículo a los que la norma injusta transgreda, y por tal transgresión declarar que la norma injusta vulnera a la constitución en tal o cual parte o dispositivo, si fracasa en esa tentativa, creemos que le basta al juez declarar que la norma injusta que desaplica viola a la constitución en su preámbulo, cuando éste enuncia la cláusula de afianzar la justicia. Bidart Campos, G., Tratado Elemental de Derecho Constitucional Argentino, ya citado, pág. 71. En el mismo sentido Sagüés, N., op. cit., pág. 65.

${ }^{40}$ Conf. Bidart Campos, G., Tratado Elemental de Derecho Constitucional Argentino, ya citado, pág. 68; Linares Quintana, S., Tratado de la Ciencia del Derecho Constitucional Argentino y Comparado, Bs. As., 1953, T. II, pág. 433; Sagüés, N., op. cit., pág 66.
} 
b) cuando la solución se busca fuera del propio orden normativo, recurriendo a la «justicia material» y los principios generales del derecho, se habla de «heterointegración». ${ }^{41}$

En cuanto a cuál debe ser la tarea del juez frente a una laguna normativa, si debe resolver o no el caso, parece existir consenso doctrinario en afirmar que el juez debe «llenar» la laguna ${ }^{42}$ recurriendo según el caso a cualquiera de los dos mecanismos descriptos arriba, privilegiando la autointegración por sobre la heterointegración.

La principal herramienta para «autointegrar» el sistema jurídico, de acuerdo a esta posición, es la analogía. La analogía es comúnmente utilizada por los juristas para extender el ámbito de aplicabilidad de las normas existentes. Para ello recurren a diferentes procedimientos retóricos de larga tradición: los argumentos a fortiori -sea a maiori ad minus o a minori ad maius- y los argumentos a pari o a simili, considerados por la dogmática tradicional como razonamientos propios de la lógica formal.

Sin embargo se ha demostrado que los argumentos por analogía tal como los usa la dogmática jurídica son, en general, lógicamente inválidos y que es falso que los aforismos en los que parecen apoyarse -por ejemplo, «quien tiene derecho a lo más tiene derecho a lo menos», «si está prohibido lo menos está prohibido lo más»- sean reductibles a operaciones lógicas o que constituyan reglas o preceptos lógicos. ${ }^{43}$ Los argumentos a fortiori y a pari, especies del argumento por analogía, tal como se los utiliza en el discurso jurídico, no son lógicamente válidos. En efecto, en general se introducen en estas argumentaciones premisas implícitas las cuales, para el caso en que sean falsas, no justificarían la verdad de la conclusión. Si las premisas implícitas están contenidas en el sistema jurídico, la conclusión será lógicamente válida, pero no permitirá ampliar el ámbito de aplicación de norma alguna para colmar una laguna, dado que sólo se habrán explicitado las consecuencias lógicas que ya formaban parte del sistema. Para poder extender el ámbito de aplicación de una norma, las premisas implícitas deberán buscarse fuera del sistema, con lo que la conclusión no estaría justificada a partir del sistema jurídico sino a partir del sistema axiológico del intérprete. ${ }^{44}$

\footnotetext{
${ }^{41}$ Conf. Bidart Campos, G., Tratado Elemental de Derecho Constitucional Argentino, ya citado, pág. 68.; Sagüés, N., op. cit., págs. 67 y 68.

${ }^{42}$ Conf. Bidart Campos, Tratado Elemental de Derecho Constitucional Argentino, ya citado, pág. 70; Sagüés, N., op. cit., pág. 67. Con relación al papel de la analogía véase también Vanossi, J., Teoría Constitucional, Bs, As., 1975, T. II, pág. 471.

${ }^{43}$ Alchourrón, C., Los argumentos jurídicos a fortiori y a pari, en Alchourrón, C. y Bulygin, E., Análisis Lógico y Derecho, ya citado, págs. 3 y ss.

${ }^{44}$ De acuerdo con Alchourrón, en los razonamientos por analogía se presuponen como premisas implícitas: a) la existencia de una cierta relación entre la conducta normada y aquella respecto de la cual se pretende determinar su calificación deóntica como conclusión del razonamiento
} 
La mayoría de los juristas, parecen preferir esta última opción y estar dispuestos a pagar en moneda de racionalidad la ilusión de convertirse en legislador.

Esto nos demuestra que la autointegración, entendida como una técnica para solucionar el problema de las lagunas utilizando únicamente normas del sistema jurídico, no es más que una nueva violación de la ley de Hume, desde el momento en que se presenta como derivadas lógicamente del sistema jurídico soluciones que han sido obtenidas a partir de premisas extrasistemáticas. En consecuencia podemos afirmar que la distinción entre autointegración y heterointegración carece de todo sentido, ya que la primera puede reducirse a la segunda, dado que en ambos casos la solución se encuentra fuera del sistema.

\section{La cuestión en torno a los términos teóricos de la dogmática constitucional}

Como hemos visto al analizar los aspectos metodológicos de la dogmática constitucional, la asunción de ciertos presupuestos filosóficos parecen incidir directamente en la comisión de la falacia de Hume.

Pero, por otra parte, la dogmática constitucional maneja, como cualquier otra disciplina, ciertos conceptos teóricos para llevar adelante su tarea. Conceptos tales como el principio de legalidad, la supremacía constitucional, el estado de sitio, la arbitrariedad, la intervención federal, entre otros, son habituales en cualquier desarrollo de su labor.

Algunos de estos conceptos resultan problemáticos desde la perspectiva bajo análisis, pues también parecen conducir al paso vedado de lo descriptivo a lo prescriptivo. Estudiaremos los conceptos de razonabilidad, poder de policía y derechos humanos. El primero ha jugado un importante rol en materia de control de constitucionalidad. El segundo ha sido y es utilizado para la justificación de limitaciones a los derechos constitucionales. Con relación al tercero, incursionaremos en la problemática de su fundamentación.

\section{a) Razonabilidad}

La noción de razonabilidad se vincula con el concepto de debido proceso legal, el cual fuera elaborado en el seno de la Corte Suprema de los Estados Unidos a partir de la interpretación de las enmiendas V y XIV con las

y; b) el carácter hereditario de la calificación deóntica existente en el sistema respecto de la relación antes mencionada. La verdad de la primera premisa implícita podría considerarse simplemente derivada del significado de las conductas analizadas. Respecto de la segunda, Alchourrón advierte con claridad que no es necesariamente verdadera, sino que su verdad dependerá de lo que en concreto nos diga el sistema jurídico en cuestión y el contexto de la situación considerada. Conf. Alchourrón, C., op. cit., págs. 9 a 14 . 
características de una garantía innominada y genérica de la libertad jurídica individual. El due process of law ha sido interpretado como haciendo referencia, por un lado, al conjunto de procedimientos que deben legalmente cumplirse para que una ley, sentencia o resolución administrativa sea formalmente válida (aspecto adjetivo del debido proceso), y por el otro, a que los actos cuenten con un cierto contenido de justicia (aspecto sustantivo del debido proceso legal). Con este último aspecto es que se identifica principalmente la idea de razonabilidad. ${ }^{45}$

La razonabilidad o debido proceso legal sustantivo consistiría en un patrón de justicia que permitiría establecer la validez axiológica de las normas, esto es, que ellas se ajustan o son conformes al valor justicia. ${ }^{46}$

Así, se ha manifestado que este principio podría expresarse de la siguiente manera: «nadie puede ser obligado a hacer lo que la ley justa no manda ni privado de hacer lo que la leyjusta no prohibe» ${ }^{47}$.

Es decir, para que una norma sea constitucional, además de cumplir con ciertos requisitos formales, debe responder a ciertas pautas de valor suficientes: «es menester dar contenido material de justicia al principio formal de legalidad $\rangle^{48}$.

\footnotetext{
${ }^{45}$ Según Linares es en 1855 cuando la Corte Suprema de los Estados Unidos la invoca por vez primera (Murray vs. Hoboken Land and Improvement Co.) y es con el caso «Chicago Milwaukee vs. Saint Paul Minnesota» (134 US 418) cuando pasa a ser no sólo una garantía procesal para ser también una categoría de tipo estimativo, un recurso técnico-axiológico que limita el poder del legislador. A partir de 1910, bajo la influencia de jueces como Holmes, Brandeis, Cardozo y Stone comienza a otorgársele un perfil más sociológico, «son las circunstancias del caso, probadas por medios convincentes, o sea los hechos sociales que motivaron la ley y los fines sociales que ellas persiguen, los datos esenciales para determinar la razonabilidad de dicho acto legislativo...» Linares, J., Razonabilidad de las leyes (el «debido proceso» como garantía innominada en la Constitución argentina), Buenos Aires, 1970.

${ }^{46}$ Conf. Bidart Campos, G., Tratado Elemental de Derecho Constitucional Argentino, ya citado, pág. 228. y Linares, F., op. cit., 30. La Corte Interamericana de Derechos Humanos ha dicho que la razonabilidad «implica un juicio de valor y, aplicada a una ley, una conformidad con los principios del sentido común». Se utiliza, igualmente, referida a parámetros de interpretación de los tratados y, por consiguiente, de la Convención. Siendo razonable lo justo, lo proporcionado y lo equitativo, por oposición a lo injusto, absurdo y arbitrario, es un calificativo que tiene contenido axiológico que implica opinión pero, de alguna manera, puede emplearse jurídicamente como, de hecho, lo hacen con frecuencia los tribunales, pues toda actividad estatal debe no solamente ser válida sino razonable. Ciertas atribuciones de la Comisión Interamericana de Derechos Humanos (arts. 41, 42, 44, 46, 47, 50 y 51 de la Convención Americana sobre Derechos Humanos), Opinión Consultiva OC-13/93 del 16 de julio de 1993. Serie A No. 13, párr. 33 y caso Paniagua Morales y otros, sentencia de excepciones preliminares, 25/1/96.

${ }^{47}$ Bidart Campos, G., Tratado Elemental de Derecho Constitucional Argentino, ya citado, pág. 227. En el mismo sentido Padilla, M., op. cit., pág. 107; Zarini, H., Análisis de la Constitución Nacional, Bs. As., 1986, pág. 88. 228.

${ }^{48}$ Bidart Campos, G., Tratado Elemental de Derecho Constitucional Argentino, ya citado, pág.
} 
En el derecho argentino, el principio de razonabilidad se encontraría principalmente receptado por el art. 28 de la Constitución Nacional, el cual establece que «Los principios, garantías y derechos reconocidos en los anteriores articulos, no podrán ser alterados por las leyes que reglamenten su ejercicio». ${ }^{49}$

Consecuentemente, una norma sería irrazonable en la medida en que se produzca la alteración que menciona el artículo 28. Al respecto, se ha dicho que «... la alteración que aqui se menciona significa cambiar la esencia o forma de una cosa, esto es, aquello que, en el caso de los derechos, es inseparable de su naturaleza profunda... La alteración de un derecho constituye una reglamentación irrazonable del mismo, puesto que lo priva de su esencialidad $\rangle^{50}$. Asimismo, la razonabilidad exige que el medio elegido por el legislador para alcanzar un fin determinado guarde proporción con este último.

Con este principio se introduce como condición sine qua non para la constitucionalidad de una norma su adecuación a determinados parámetros axiológicos o morales. Ahora bien, cuando se habla de «contenido material de justicia» cabe preguntarse si se está haciendo referencia a un sistema de moral positiva vigente de hecho en una sociedad, en un momento y lugar determinados, a una moral ideal o crítica, o a principios previstos en la propia Constitución.

En muchos casos se pretende hacer referencia a una «moral ideal o crítica» de principios y reglas «objetivos». ${ }^{51} \mathrm{Ya}$ analizamos los problemas que la adopción de una posición tal lleva aparejados. Sin embargo, agregaremos a lo dicho una consideración crítica: desde el momento en que el principio de razonabilidad implica una serie de reglas cuya verificación intersubjetiva es por lo menos dificultosa, se corre el riesgo de presentar con rasgos de objetividad las propias valoraciones del intérprete.

Menor parece ser el riesgo de violar la ley de Hume cuando el concepto de razonabilidad es entendido en términos de una moral positiva. Así por ejemplo se ha señalado que «... el acto legislativo, razonable internamente, debe satisfacer el sentido común jurídico de la comunidad expresado en el plexo de valores que lo integran: valores que son recibidos, de acuerdo con las modalidades de cada pueblo, por la Constitución del Estado (dicho sentido

${ }^{49}$ Quiroga Lavié., H., op. cit., pág. 468, agrega a esta norma el artículo 18 con relación a las decisiones judiciales y el actual art. 99 inic. 2 en relación con la reglamentación de las leyes.

${ }^{50}$ Padilla, M., op. cit., pág. 107.

${ }^{51}$ Ver Bidart Campos, G., Tratado Elemental de Derecho Constitucional Argentino, ya citado, pág. 228; Linares, J., op. cit., pág. 52; Padilla, M., op. cit., cap. 1 y pág. 107; Sagüés, N., op. cit., pág. 140, quien considera que el Derecho Natural se encuentra incorporado a la constitución argentina través del artículo 33. 
está expresado también en el preámbulo de la Constitución) $\rangle^{52}$. No obstante, al tomarse como parámetro a una moral positiva, deberíamos en primer término resolver quién sería competente para interpretar la moral media de una sociedad, previa aceptación de que el intérprete, por ejemplo el juez, es capaz de conocer las preferencias de su comunidad frente a cada caso concreto a resolver.

Como vemos, este concepto de razonabilidad, tal como se lo utiliza en la mayoría de los casos, constituye un nuevo salto de lo descriptivo a lo prescriptivo. Creemos que tal vez la solución esté en retrotraer la expresión de usos metafísicos y concepciones esencialistas como las arriba analizadas hacia los textos constitucionales que, en la actualidad especialmente a través de las declaraciones de derechos y tratados internacionales brindan sobrados parámetros para establecer si el contenido de una norma es constitucional o no.

\section{b) Poder de policía}

Para la dogmática constitucional, (y también según la jurisprudencia de la Corte Suprema argentina) existen dos conceptos del instituto bajo análisis: uno restringido y uno amplio.

El primero, de origen europeo, sostiene que es la porción del poder estatal que limita los derechos individuales con el único objetivo de tutelar la salubridad, moralidad y seguridad de la población.

La acepción amplia, construida por la doctrina judicial estadounidense, admite que los derechos se reglamenten en función de cualquier objetivo que se dirija al bienestar general de la población o al bien común. Quedarían entonces sujetas al poder de policía cuestiones no sólo vinculadas con los objetivos antedichos, sino también las emparentadas con aspectos económicos y de bienestar general.

Las diferentes concepciones o «clases» de poder de policía solo parecen obedecer a una cuestión de gradación en la facultad reglamentaria del estado. Para algunos, dicha expresión sólo refiere a ciertos aspectos -salubridad, moralidad y seguridad- de la mencionada facultad. Para otros, designa la facultad genérica del estado de reglamentar los derechos en aras del bien común o interés general.

Creemos detectar en el uso de esta expresión resabios de una concepción esencialista del lenguaje, en tanto se pretende demostrar un «verdadero significado» del término «poder de policía». Pero asimismo, y eso se hace tal vez más explícito en algunos fallos jurisprudenciales, existe también una cierta definición persuasiva del término, ya que se manipula su significación

\footnotetext{
${ }^{52}$ Quiroga Lavié, H., op. cit., pág. 464.
} 
para la justificación, sea de una restricción de los poderes reglamentarios del estado a los cometidos expresados, o bien para una ampliación de los mismos. ${ }^{53}$

La discusión en torno a los alcances de la expresión «poder de policía» va más allá de una simple cuestión terminológica. Se discute en definitiva en torno a la extensión del poder de los órganos políticos para limitar los derechos individuales, y los juicios en favor de una u otra posición son presentados en muchos casos bajo el ropaje de objetivas elucidaciones conceptuales. Coincidimos con Carlos $\mathrm{Nino}^{54}$ en que expresiones como «poder de policía» ocultan la posibilidad de determinar las razones que justifican la limitación de un derecho y entorpecen la discusión racional tan necesaria en la práctica constitucional.

\section{c) Derechos humanos}

Sin duda, uno de los temas en el que más tinta ha corrido en el área del derecho constitucional en los últimos tiempos es respecto de la problemática de los derechos humanos. Una de las polémicas más interesantes en este sentido se vincula con qué debe entenderse por la expresión «derechos humanos», lo que a su vez guarda estrecha relación con el problema de su fundamentación.

Algunos buscan el fundamento de los derechos humanos en una instancia suprapositiva, como sería el derecho natural. Para el iusnaturalismo los derechos humanos preexisten al derecho positivo y la única función del derecho será reconocerlos. ${ }^{55}$

Las dificultades ya analizadas que conlleva la afirmación de la existencia de un derecho natural obviamente se proyectan a la noción de derechos humanos. De esta manera, si no es posible determinar cuáles son esos principios inmutables que conforman el estrato normativo supraempírico del derecho natural, cabe preguntarse sobre qué bases construye un iusnaturalista una noción como la de los «derechos humanos». En este camino muchos autores han intentado superar la concepción iusnaturalista dieciochesca de los derechos humanos.

${ }^{53}$ Así, Quiroga Lavié habla de poder de policía en sentido liberal y en sentido intervencionista. Ver op. cit., págs. 230 y 231.

${ }^{54}$ Nino, C., Fundamentos de derecho constitucional, Bs. As., 1992, pág. 493.

${ }^{55}$ Conf. Fernández Galiano, A., Carta al profesor Javier Muguerza, en Muguerza J., y otros El fundamento de los derechos humanos, Madrid, 1989, pág, 166. Gran parte de la dogmática constitucional argentina abreva en esta postura. Véase Bidart Campos, G., Dogmática constitucional de los derechos humanos. (El derecho natural en el derecho constitucional de los derechos humanos), ya citado; Padilla, M., op. cit., págs. 27 y ss., entre otros. 
En los últimos años algunos autores han propuesto concebirlos como derechos morales, tal el caso de Carlos Nino, para quien los derechos humanos derivan de un sistema de principios morales pertenecientes a una moral crítica o ideal que responden a los caracteres de universalidad, autonomía, finalidad, superveniencia, etc. Para Nino, los derechos humanos tienen las mismas características que para un iusnaturalista tradicional, sólo que en vez de sostener que son derechos jurídicos, afirma que son derechos morales. ${ }^{56}$ Ello es así porque la «moral ideal o crítica» está conformada por principios de validez objetiva, circunstancia que la asimila finalmente al derecho natural. ${ }^{57}$

Por su lado el Profesor Pérez Luño, no obstante rechazar la idea de un derecho natural como un código absoluto e inmutable, caracteriza los derechos humanos como «un conjunto de facultades e instituciones que, en cada momento histórico, concretan las exigencias de la dignidad, la libertad y la igualdad humanas, las cuales deben ser reconocidas positivamente por los ordenamientos jurídicos a nivel nacional $e$ internacional $\rangle^{58}$. Para el profesor español los derechos humanos se fundamentarían en tres valores: la dignidad, la libertad y la igualdad humanas. Estos valores importarían exigencias intrínsecas del ser humano constantes y permanentes que a lo largo de la historia se concretan y especifican a través de los distintos derechos humanos, exigencias que deberían ser reconocidas por el ordenamiento jurídico para que pasen a ser derechos humanos. Esta propuesta parece muy cercana a la idea de un derecho natural con contenido progresivo y creemos que es posible de las mismas críticas que esbozáramos más arriba.

Cabe entonces concluir que toda caracterización de corte iusnaturalista de los derechos humanos parece conducir a la comisión de la falacia de Hume.

Consideramos que otra sería la situación si la expresión «derechos humanos» fuera caracterizada desde el marco teórico del positivismo. Tradicionalmente se han atribuido al positivismo diferentes tesis en torno a la conceptualización que del derecho en general hace y consecuentemente de los derechos humanos en particular. Y hacemos hincapié en la palabra atribuir, dado que muchas de las afirmaciones que se presentan como de cuño positivista no han sido realmente sostenidas por los positivistas sino que le han sido adjudicadas por sus detractores.

${ }^{56}$ Conf. Nino, C.. Ética y Derechos Humanos, Bs. As., 1989 e Introducción al análisis del derecho, ya citado, pág. 196.

${ }^{57}$ Conf. Bulygin E., «Sobre el status ontológico de los derechos humanos», en Análisis lógico y derecho, ya citado, pág. 622.

${ }^{58}$ Pérez Luño, E., Sobre los valores fundamentadores de los derechos humanos, en Muguerza, J. y otros, El fundamento de los derechos humanos, ya citado, pág. 279. Ver también «Concepto y concepción de los derechos humanos (acotaciones a la ponencia de Francisco Laporta)» en Doxa 4, Alicante, 1987. 
Sobre todo en materia de derechos humanos, es harto común que se identifique al positivismo a través de diversas tesis que ninguno de los más renombrados positivistas, como Kelsen, Hart o Ross, han sostenido jamás. ${ }^{59}$ Es común reducir al positivismo a lo que Norberto Bobbio denominara "positivismo ideológico» y Alf Ross «seudopositivismo», como afirmación de que cualquiera sea el contenido de las normas del derecho positivo, por el sólo hecho de ser positivo y contar con el monopolio de la fuerza estatal, debe ser obedecido por los súbditos y aplicado por los jueces, haciendo caso omiso de sus propias valoraciones. ${ }^{60}$

Como vemos éste sería el perfil del positivismo del que habla Peces-Barba, expresión de «cinismo pragmático de los adoradores del poder, y de la justificación del poder por el poder, para los cuales el derecho es sólo un instrumento técnico al servicio de aquél, una justificación de sus decisiones de voluntad» ${ }^{61}$. En definitiva, se trata de un enemigo hecho a medida.

Si en cambio caracterizamos al positivismo como aquella postura que sostiene conjuntamente las siguientes dos tesis:

- el derecho debe ser definido en términos puramente formales dejando de lado toda propiedad valorativa;

- no existe un derecho natural, es decir, se niega la existencia de un sistema de normas morales objetivamente válidas y cognoscibles por el hombre. ${ }^{62}$

resulta en materia de fundamentación de los derechos humanos que si no existen principios o normas morales absolutas, tampoco podremos hablar de lo que en términos de Nino serían derechos morales y derechos humanos con rasgos de universalidad, generalidad, etc. Esto sin embargo no nos lleva a negar la existencia de derechos morales o derechos humanos. Sólo negamos su pretensión de validez absoluta. Los derechos humanos serían exigencias que se formulan a un ordenamiento jurídico desde un determinado sistema moral: «los derechos humanos no son algo dado, sino una exigencia o pretensión ${ }^{63}$.

\section{Conclusión}

No caben dudas del importante rol que ha ejercido y ejerce la doctrina en la práctica constitucional, no sólo por haberse constituido en referencia

\footnotetext{
${ }^{59}$ Conf. Bulygin, E., Sobre el status ontológico de los derechos humanos, ya citado, pág. 621.

${ }^{60}$ Conf. Nino, C., Introducción al análisis del derecho, ya citado, pág. 33. Ver Bobbio, N., El problema del positivismo jurídico, México, 1993; Ross, A., El concepto de validez y otros ensayos, México 1993.

${ }^{61}$ Peces-Barba, G., Escritos sobre derechos fundamentales, Madrid, 1988, pág. 219.

${ }^{62}$ Conf. Bulygin, E., Sobre el status ontológico de los derechos humanos, ya citado, pág. 623.

${ }^{63}$ Bulygin, E., Sobre el status ontológico de los derechos humanos, ya citado, pág. 624.
} 
obligada de todo operador del derecho -jueces, legisladores, abogados, funcionarios-, sino también por el papel que desempeña en la formación jurídica de los ciudadanos.

Como todo científico, el jurista tiene derecho a elegir dentro de qué marco filosófico-teórico y con qué herramientas acometerá el estudio de su objeto. En este sentido hemos querido señalar algunos de los problemas que trae aparejada la asunción de una base filosófica de corte iusnaturalista y de un paradigma como el instaurado a partir del siglo XIX en la ciencia jurídica del sistema continental. Así, hemos visto que tanto con relación a la tarea interpretativa como respecto de ciertos términos teóricos específicos de la disciplina, el marco escogido ha llevado en reiteradas ocasiones a la comisión de la falacia de Hume.

Coincidimos con Carlos Nino en que no es objetable que la dogmática más allá de su tarea descriptiva efectúe valoraciones, lo censurable es que lo haga en forma encubierta. ${ }^{64}$ $\mathrm{Y}$ es entonces cuando vislumbramos que los peligros de caer en la falacia no se agotan en lo meramente epistemológico. El aumento de la discrecionalidad y el autoritarismo, con la correlativa disminución de la seguridad jurídica son sólo algunas de sus proyecciones, sobre todo si lo que se está interpretando es una constitución, pilar fundamental de la tutela los derechos humanos y del Estado de Derecho. Es por ello que se plantea como una necesidad vital de las democracias modernas una ciencia jurídica que, dejando de lado todo recurso retórico o eufemístico, contribuya mediante una argumentación racional a la democratización de la práctica constitucional.

${ }^{64}$ Nino, C., Fundamentos de derecho constitucional, ya citado, pág. 103. 
DOXA 21-I (1998) 